\title{
Solution of Thermoelectricity Problems Energy Method
}

\author{
Muheyat Niyazbek ${ }^{1}$, Nogaybaeva M.O ${ }^{3}$, Kuenssaule Talp ${ }^{2 . *}$, Kudaikulov A.A ${ }^{3}$ \\ ${ }^{1}$ College of Information Science and Engineering, Xinjiang University, Urumqi, China ,830046 \\ ${ }^{2}$ College of Chinese Medicine of Xinjiang Medical University, Urumqi, Xinjiang, China 830011 \\ ${ }^{3}$ Al-Farabi Kazakh National University, Kazakhstan, Almaty
}

\begin{abstract}
On the basis of the fundamental laws of conservation of energy in conjunction with local quadratic spline functions was developed a universal computing algorithm, a method and associated software, which allows to investigate the Thermophysical insulated rod, with limited length, influenced by local heat flow, heat transfer and temperature
\end{abstract}

\section{Introduction}

Supporting elements of modern gas-power plants ${ }^{1}$, nuclear and thermal power plants, hydrogen and jet engines, internal combustion engines, deep processing of mineral raw materials and oil rigs are operating in the complex field of power and heat. The reliability of the above mentioned plants depend on the characteristics of the hot-bearing elements. The elements considered as bearing rods of limited length and of constant cross section ${ }^{[1] ~[2]}$. In these problems, based on the fundamental laws of Thermal Physics [3] was determined the temperature distribution of the field along the length of the rod of limited length in view of the existing types of heat sources. Other similar problems were considered in [4-6]. This study was to determine the law of temperature distribution along the length of the test bar depending on the types of specified heat sources. In this paper, a horizontal rod of limited length and constant cross section is considered as a carrier element of construction. And the lateral surface of the test rod is completely insulated. The cross-sectional area of the left end of the rod is under heat flux with constant intensity. The crosssectional area of the right end of the rod has a heat exchange with the ambient environment area. But, in the simultaneous presence of different types of heat sources in the supporting elements of the strategic structures there are axial compressive forces, displacement distribution field, elastic, thermal and thermo-elastic deformations of components and related stress, in addition to the distribution of temperature field. Therefore, the development of fundamental methods for deep study of complex thermo-physical states of bearing structural elements is an actual problem of Applied Thermophysics. In this work following statements were defined with the help of the fundamental laws of conservation of energy ${ }^{[7]}$

1) The law of the temperature distribution along the length of the rod;

2) The value of its thermal expansion;

3) The value of the arising axial compressive force;

4) The law of distribution of elastic, thermal and thermoelastic components of the strain and stress;

5) The displacement field.

We consider the horizontal rod, with limited length $\mathrm{L}$ [см] and constant cross-sectional area $\mathrm{F}$ [см2]. The cross-section of the rod can be circular, quadrilateral, triangula

\section{Conclusion of resolving equations}

Thermal properties of the rod material characterized by a coefficient of thermal expansion of the material of the $\operatorname{rod} \alpha\left[\frac{1}{{ }_{0} \mathrm{C}}\right]$, thermal conductivity $\mathrm{\kappa x}\left[\frac{\mathrm{BT}}{\mathrm{CM} *{ }^{\circ} \mathrm{C}}\right]$, as well as the modulus of elasticity $\mathrm{\kappa x}\left[\frac{\mathrm{BT}}{\mathrm{CM} *{ }^{\mathrm{C} C}}\right]$.

The cross-sectional area of the left end of the rod is under heat flux $\mathrm{q}\left[\frac{\mathrm{BT}}{\mathrm{cm}^{2}}\right]$. Under the influence of the local heat flow the surface value of heat flux is negative, that is $\mathrm{q}<0$. The cross-sectional area of the right end of the rod is under a convective heat transfer with the surrounding environment. Here, heat exchange coefficient is $\mathrm{h}\left[\frac{\mathrm{BT}}{\mathrm{cm}^{2} \mathrm{C}}\right]$, and ambient temperature is $\mathrm{T}_{{ }^{\circ} \mathrm{C}}\left[{ }^{\circ} \mathrm{C}\right]$. First must be determined the temperature distribution along the length of the test rod depending on the type of existing heat sources, thermal and geometrical characteristics of the rod. To do this, first we build a local approximational quadratic spline function.

Design scheme of the problem is shown in Figure 1.

Figure 1 - Diagram of the problem Suppose that 


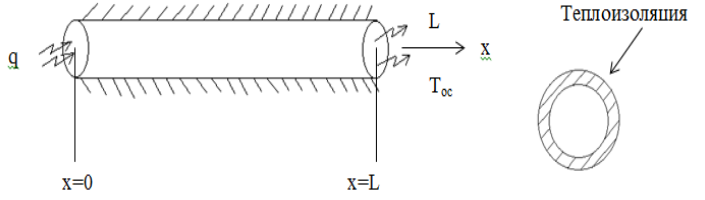

$$
\mathrm{T}(\mathrm{x}=0)=\mathrm{T}_{\mathrm{i}} ; \mathrm{T}\left(\mathrm{x}=\frac{\mathrm{L}}{2}\right)=\mathrm{T}_{\mathrm{j}} ; \mathrm{T}(\mathrm{x}=\mathrm{L})=\mathrm{T}_{\mathrm{k}}
$$

Approximate the full second-order polynomial spline functions of the distribution of temperature along the length of the test rod [8]

$\mathrm{T}(\mathrm{x})=\mathrm{ax}^{2}+\mathrm{bx}+\mathrm{c}=\varphi_{\mathrm{i}}(\mathrm{x}) * \mathrm{~T}_{\mathrm{i}}+\varphi_{\mathrm{j}}(\mathrm{x}) * \mathrm{~T}_{\mathrm{j}}+$ $\varphi_{\mathrm{k}}(\mathrm{x}) * \mathrm{~T}_{\mathrm{k}} ; 0 \leq \mathrm{x} \leq \mathrm{L}$

Where:

$\varphi_{\mathrm{i}}(\mathrm{x})=\frac{2 \mathrm{x}^{2}-3 \mathrm{Lx}+\mathrm{L}^{2}}{\mathrm{~L}^{2}} ; \varphi_{\mathrm{j}}(\mathrm{x})=\frac{4 \mathrm{Lx}-4 \mathrm{x}^{2}}{\mathrm{~L}^{2}} ; \quad \varphi_{\mathrm{k}}(\mathrm{x})=\frac{2 \mathrm{x}^{2}-\mathrm{Lx}}{\mathrm{L}^{2}} ;$ $0 \leq \mathrm{x} \leq \mathrm{L}$

Now we write functional for the problem that characterizes the law of conservation of energy [7]

$\mathrm{J}=\int_{\mathrm{S}(\mathrm{x}=0)} \mathrm{qTdS} \int+\int_{\mathrm{V}} \frac{\mathrm{kxx}}{2}\left(\frac{\partial \mathrm{T}}{\partial \mathrm{x}}\right)^{2} \mathrm{dV}+$ $\int_{\mathrm{S}(\mathrm{x}=\mathrm{L})} \frac{\mathrm{h}}{2}\left(\mathrm{~T}-\mathrm{T}_{\mathrm{OC}}\right)^{2} \mathrm{dS}$,

It should be noted that the dimension of each member is $\left[\mathrm{BT}^{\circ} \mathrm{C}\right]$. This is the work carried out by temperature, work force $\left[\mathrm{K}^{*} \mathrm{~cm}\right]$. Due to the physical nature of the phenomenon, we have:

$$
\mathrm{J}_{1}=\int_{\mathrm{S}(\mathrm{x}=0)} \mathrm{q} * \mathrm{TdS}=\mathrm{FqT}_{\mathrm{i}}
$$

$$
\mathrm{J}_{3}=\int_{\mathrm{S}(\mathrm{x}=\mathrm{L})} \frac{\mathrm{h}}{2}\left(\mathrm{~T}-\mathrm{T}_{\mathrm{OC}}\right)^{2} \mathrm{dS}=\frac{\mathrm{Fh}}{2}\left(\mathrm{~T}_{\mathrm{k}}-\mathrm{T}_{\mathrm{OC}}\right)^{2}
$$

For the calculation of the integral over the volume of equation (4), it is necessary to determine the temperature gradient

$\frac{\partial \mathrm{T}}{\partial \mathrm{x}}=\frac{\partial \varphi_{\mathrm{i}}}{\partial \mathrm{x}} \mathrm{T}_{\mathrm{i}}+\frac{\partial \varphi_{\mathrm{j}}}{\partial \mathrm{x}} \mathrm{T}_{\mathrm{j}}+\frac{\partial \varphi_{\mathrm{k}}}{\partial \mathrm{x}} \mathrm{T}_{\mathrm{k}}=\frac{4 \mathrm{x}-3 \mathrm{~L}}{\mathrm{~L}^{2}} \mathrm{~T}_{\mathrm{i}}+\frac{4 \mathrm{~L}-8 \mathrm{x}}{\mathrm{L}^{2}} \mathrm{~T}_{\mathrm{j}}+$
$\frac{4 \mathrm{x}-\mathrm{L}}{\mathrm{L}^{2}} \mathrm{~T}_{\mathrm{k}}, 0 \leq \mathrm{x} \leq \mathrm{L}$

Then substituting (7) in terms of $\mathrm{J}$, and using the known formula

$\int_{V} f(x) d V=F \int_{0}^{L} f(x) d x$ we have

$$
\begin{gathered}
\mathrm{J}_{2}=\int_{\mathrm{V}} \frac{\mathrm{k}_{\mathrm{x}}}{2}\left(\frac{\partial \mathrm{T}}{\partial \mathrm{x}}\right)^{2} \mathrm{dV}=\frac{\mathrm{Fk}_{\mathrm{x}}}{\partial \mathrm{x}}\left(7 \mathrm{~T}_{\mathrm{i}}^{2}-16 \mathrm{~T}_{\mathrm{i}} \mathrm{T}_{\mathrm{j}}+\right. \\
\left.2 \mathrm{~T}_{\mathrm{i}} \mathrm{T}_{\mathrm{k}}-16 \mathrm{~T}_{\mathrm{j}} \mathrm{T}_{\mathrm{k}}+16 \mathrm{~T}_{\mathrm{j}}^{2}+7 \mathrm{~T}_{\mathrm{k}}^{2}\right)
\end{gathered}
$$

Then, an integrated form of the complete thermal energy functional is:

$$
\begin{aligned}
\mathrm{J}=\mathrm{J}_{1}+\mathrm{J}_{2}+\mathrm{J}_{3}= & \\
& =\mathrm{FqT}_{\mathrm{i}} \\
& +\frac{\mathrm{Fk}_{\mathrm{i}}}{\partial \mathrm{x}}\left(7 \mathrm{~T}_{\mathrm{i}}^{2}-16 \mathrm{~T}_{\mathrm{i}} \mathrm{T}_{\mathrm{j}}+2 \mathrm{~T}_{\mathrm{i}} \mathrm{T}_{\mathrm{k}}\right. \\
& \left.-16 \mathrm{~T}_{\mathrm{j}} \mathrm{T}_{\mathrm{k}}+16 \mathrm{~T}_{\mathrm{j}}^{2}++7 \mathrm{~T}_{\mathrm{k}}^{2}\right) \\
+\frac{\mathrm{Fh}}{2}\left(\mathrm{~T}_{\mathrm{k}}-\mathrm{T}_{\mathrm{OC}}\right)^{2} &
\end{aligned}
$$

It should be noted that for determining the values of $\mathrm{T}_{\mathrm{i}}, \mathrm{T}_{\mathrm{j}}$ и $\mathrm{T}_{\mathrm{k}}$ We need to get the corresponding system of linear algebraic equations, which take into account all existing natural boundary conditions, varying from $\mathrm{J}$ to $\mathrm{T}_{\mathrm{i}}, \mathrm{T}_{\mathrm{j}}$ и $\mathrm{T}_{\mathrm{k}}$.

$$
\begin{aligned}
& \frac{\partial \mathrm{J}}{\partial \mathrm{T}_{\mathrm{i}}}=0 ; \rightarrow \mathrm{Fq}+\frac{\mathrm{Fk}_{\mathrm{x}}}{6 \mathrm{~L}}\left(14 \mathrm{~T}_{\mathrm{i}}-16 \mathrm{~T}_{\mathrm{j}}+2 \mathrm{~T}_{\mathrm{k}}\right)=0 \\
& \frac{\partial \mathrm{J}}{\partial \mathrm{T}_{\mathrm{j}}}=0 ; \rightarrow \frac{\mathrm{Fk}_{\mathrm{x}}}{6 \mathrm{~L}}\left(-16 \mathrm{~T}_{\mathrm{i}}+32 \mathrm{~T}_{\mathrm{j}}-16 \mathrm{~T}_{\mathrm{k}}\right)=0
\end{aligned}
$$

$$
\begin{gathered}
\frac{\partial \mathrm{J}}{\partial \mathrm{T}_{\mathrm{k}}}=0 ; \rightarrow \frac{\mathrm{Fk}_{\mathrm{x}}}{6 \mathrm{~L}}\left(2 \mathrm{~T}_{\mathrm{i}}-16 \mathrm{~T}_{\mathrm{j}}+14 \mathrm{~T}_{\mathrm{k}}\right)+\mathrm{FhT}_{\mathrm{k}}-\mathrm{FhT}_{\mathrm{OC}} \\
=0
\end{gathered}
$$

After simplification, we have

$7 \mathrm{~T}_{\mathrm{i}}-8 \mathrm{~T}_{\mathrm{j}}+\mathrm{T}_{\mathrm{k}}=-\frac{3 \mathrm{Lq}}{\mathrm{k}_{\mathrm{x}}}$

$\mathrm{T}_{\mathrm{i}}-2 \mathrm{~T}_{\mathrm{j}}+\mathrm{T}_{\mathrm{k}}=0$

$7 \mathrm{~T}_{\mathrm{i}}-8 \mathrm{~T}_{\mathrm{j}}+7 \mathrm{~T}_{\mathrm{k}}+\frac{3 \mathrm{Lh}}{\mathrm{k}_{\mathrm{x}}} \mathrm{T}_{\mathrm{k}}=\frac{3 \mathrm{LhT}_{\mathrm{OC}}}{\mathrm{k}_{\mathrm{x}}}$

After solving this system we define that

$$
\mathrm{T}_{\mathrm{i}}=\mathrm{T}_{\mathrm{OC}}-\frac{\mathrm{q}}{\mathrm{h}}-\frac{\mathrm{Lq}}{\mathrm{k}_{\mathrm{x}}} ; \mathrm{T}_{\mathrm{j}}=\mathrm{T}_{\mathrm{OC}}-\frac{\mathrm{q}}{\mathrm{h}}-\frac{\mathrm{Lq}}{2 \mathrm{k}_{\mathrm{x}}} ; \mathrm{T}_{\mathrm{k}}=\mathrm{T}_{\mathrm{OC}}-\frac{\mathrm{q}}{\mathrm{h}}
$$

Then substituting (12) into (2-3) and after simplifying it we define the law of temperature distribution along the length of the test rod in view of simultaneous presence of the thermal insulation, heat flux and heat transfer. It will have the following form:

$\mathrm{T}=\mathrm{T}\left(\mathrm{x}, \mathrm{T}_{\mathrm{OC}}, \mathrm{q}, \mathrm{h}, \mathrm{L}, \mathrm{k}_{\mathrm{x}}\right)=\left(\mathrm{T}_{\mathrm{OC}}-\frac{\mathrm{q}}{\mathrm{h}}-\frac{\mathrm{qL}}{\mathrm{k}_{\mathrm{x}}}\right)+\frac{\mathrm{q}}{\mathrm{k}_{\mathrm{x}}} \mathrm{x} ; 0 \leq$ $\mathrm{X} \leq \mathrm{L}$

This shows that in this case the law of the temperature distribution along the length of the test bar is linear

\section{Determination of thermophysical state of the rod}


Now we solve next problem. Because of the temperature field, the rod will extend. It is required to determine the elongation of the rod while it is under different sources of heat. To do this, we assume that the left end of the rod is rigidly fixed, and the right is free. From the general laws of thermodynamics [7-8] we known that the value of elongation of the rod from the temperature field is defined as:

$$
\Delta \mathrm{l}_{\mathrm{T}}=\int_{0}^{\mathrm{L}} \alpha \mathrm{T}(\mathrm{x}) \mathrm{dx}
$$

$$
\begin{aligned}
& \text { If assume that } \alpha=\text { const, then } \\
& \Delta \mathrm{l}_{\mathrm{T}}=\int_{0}^{\mathrm{L}} \alpha \mathrm{T}(\mathrm{x}) \mathrm{dx}=\alpha \mathrm{L}\left(\mathrm{T}_{\mathrm{OC}}-\frac{\mathrm{q}}{\mathrm{h}}-\frac{\mathrm{qL}}{2 \mathrm{k}_{\mathrm{x}}}\right)
\end{aligned}
$$

Next step is to solve the third problem. If both ends of the rod is rigidly-clamped, the rod can neither lengthen nor shorten. In this case appears an axial compression force $\mathrm{R}[\kappa \Gamma]$. It is defined as the solution of statically indeterminate problems, while applying strain compatibility conditions:

$$
\frac{\mathrm{RL}}{\mathrm{EF}}+\Delta \mathrm{L}_{\mathrm{T}}=0 \rightarrow \mathrm{R}=-\frac{\Delta \mathrm{L}_{\mathrm{T}} \mathrm{EF}}{\mathrm{L}}=-\alpha \mathrm{EF}\left(\mathrm{T}_{\mathrm{OC}}-\frac{\mathrm{q}}{\mathrm{h}}-\frac{\mathrm{qL}}{2 \mathrm{k}_{\mathrm{x}}}\right)
$$

After this the solution for the fourth problem is easily determined, defining the emerging field of thermo-elastic stress $\sigma\left[\frac{\mathrm{\kappa} \Gamma}{\mathrm{cm}^{2}}\right]$. It is determined in accordance with Hooke's law: [9]

$$
\sigma=\frac{\mathrm{R}}{\mathrm{F}}=-\alpha \mathrm{E}\left(\mathrm{T}_{\mathrm{OC}}-\frac{\mathrm{q}}{\mathrm{h}}-\frac{\mathrm{qL}}{2 \mathrm{k}_{\mathrm{x}}}\right)
$$

This shows that the thermoelastic component of the stress field distribution $\sigma$ is straight and parallel to the shaft axis and the x-axis. Using again the generalized Hooke's law we find a solution for the fifth problem of determining the thermo-elastic deformation of the component

$$
\varepsilon=\frac{\sigma}{\mathrm{E}}=-\alpha\left(\mathrm{T}_{\mathrm{OC}}-\frac{\mathrm{q}}{\mathrm{h}}-\frac{\mathrm{qL}}{2 \mathrm{k}_{\mathrm{x}}}\right)
$$

From solutions it is clear that it linear and parallel to the axis OX. If we consider that $\mathrm{q}<0$, then (16-18) shows that the $\mathrm{R}, \sigma, \varepsilon$ will compress. Next, using the fundamental laws of thermodynamics we can solve the sixth problem of determining the field of thermal strain

$$
\varepsilon_{\mathrm{T}}(\mathrm{x})=-\alpha \mathrm{T}(\mathrm{x})=-\alpha\left[\left(\mathrm{T}_{\mathrm{OC}}-\frac{\mathrm{q}}{\mathrm{h}}-\frac{\mathrm{qL}}{\mathrm{k}_{\mathrm{x}}}\right)+\frac{\mathrm{q}}{\mathrm{k}_{\mathrm{x}}} \mathrm{x}\right], \quad 0 \leq
$$$$
\mathrm{X} \leq \mathrm{L}
$$

This shows that $\varepsilon_{\mathrm{T}^{-}}$will compress and distribution of the field will be linear.

The seventh problem can be determined by using the generalized Hooke's law. Then the field distribution of the temperature stress component will be:

$$
\begin{gathered}
\sigma_{\mathrm{T}}(\mathrm{x})=\mathrm{E} \varepsilon_{\mathrm{T}}(\mathrm{x})=-\alpha \mathrm{E}\left[\left(\mathrm{T}_{\mathrm{OC}}-\frac{\mathrm{q}}{\mathrm{h}}-\frac{\mathrm{qL}}{\mathrm{k}_{\mathrm{x}}}\right)+\frac{\mathrm{q}}{\mathrm{k}_{\mathrm{x}}} \mathrm{x}\right] \\
0 \leq \mathrm{x} \leq \mathrm{L}
\end{gathered}
$$

From the decision it is clear that it has linear and squeezing character. The eighth problem of determining the field of elastic deformation of the components is determined from the fundamental law

$$
\varepsilon_{\mathrm{x}}(\mathrm{x})=\varepsilon-\varepsilon_{\mathrm{T}}(\mathrm{x})=\frac{\alpha}{\mathrm{k}_{\mathrm{x}}}\left(-\frac{\mathrm{qL}}{2}+\mathrm{qx}\right)=\frac{\mathrm{q} \alpha}{\mathrm{k}_{\mathrm{x}}}\left(-\frac{\mathrm{L}}{2}+\right.
$$

$\mathrm{x})$,

This shows that $\varepsilon_{\mathrm{x}}(\mathrm{x})$ is linear. At the length $0 \leq \mathrm{x} \leq$ $\frac{\mathrm{L}}{2}$, it has expansive character. In section $\mathrm{x}=\frac{\mathrm{L}}{2}, \varepsilon_{\mathrm{x}}\left(\frac{\mathrm{L}}{2}\right)=0$. Further it compresses.

The relevant law of Hooke determines the decision of the tenth problem

$$
\sigma_{\mathrm{x}}(\mathrm{x})=\mathrm{E} \varepsilon_{\mathrm{x}}(\mathrm{x})=\frac{\mathrm{q} \alpha \mathrm{E}}{\mathrm{k}_{\mathrm{x}}}\left(-\frac{\mathrm{L}}{2}+\mathrm{x}\right)
$$

It is similar to $\varepsilon_{\mathrm{x}}(\mathrm{x})$.

Now, finally, we decide the tenth problem of determining displacement field $\mathrm{U}(\mathrm{x})$. It is determined from the Cauchy relation

$$
\begin{aligned}
& \varepsilon_{\mathrm{x}}=\frac{\partial \mathrm{U}}{\partial \mathrm{x}}=\rightarrow \mathrm{U}(\mathrm{x})=\int \varepsilon_{\mathrm{x}}(\mathrm{x}) \mathrm{dx}=\frac{\mathrm{q} \alpha}{\mathrm{k}_{\mathrm{x}}}\left(-\frac{\mathrm{L}}{2} \mathrm{x}+\right. \\
& \left.\frac{\mathrm{x}^{2}}{2}\right)+\mathrm{C}, \text { где } \mathrm{C}=\text { const. }
\end{aligned}
$$

The value of $\mathrm{C}$ is determined from the condition of pinching the two ends, ie $\mathrm{U}(\mathrm{x}=0)=\mathrm{U}(\mathrm{x}=\mathrm{L})=0$. Then we have that $\mathrm{C}=0$. Then the field of movement is

$$
\mathrm{U}(\mathrm{x})=\frac{\mathrm{q} \alpha \mathrm{x}}{\mathrm{k}_{\mathrm{x}}}\left(\frac{\mathrm{x}}{2}-\frac{\mathrm{L}}{2}\right), 0 \leq \mathrm{x} \leq \mathrm{L}
$$

This shows that $U(\mathrm{x})$ has a quadratic form. The cross section located on the interval $0<\mathrm{x} \leq \mathrm{L}$ moves in the direction of OX.

Naturally, clamped ends do not move, ie, $\mathrm{U}(\mathrm{x}=0)=\mathrm{U}(\mathrm{x}=\mathrm{L})=0$.

\section{Conclusion}

Based on the fundamental laws of energy conservation was developed computational algorithm and method of steady thermo-physical condition of the insulated rod of limited length, which is under the heat flow and heat transfer. It was found that the temperature distribution of elastic and temperature components are linear. While the value of the thermoelastic component of the strain and stress will be constant. The distribution law of movement will have a quadratic character, and all the section of the rod will move from left to right if $\mathrm{q}<=0$ 


\section{References:}

1. Tikhonova Zh.M , Nurlybaeva E.N, Kudaykulov, A, Zhumadillaeva A.K. Numerical study of stablished Thermo-mechanical state of rods of limited length, with the presence of local heat flows, temperatures, heat Insulation and heat transfer [J]. Advanced Science Letters, 2013, 19 (8) : 2395-2397.

2. Tashenova Zh.M., Nurlybaeva E.N, Kudaykulov A. Developing a Computational Modeling Algorithm for Thermostressed Condition of Rod made of Heatresistant Material ANB-300 type [J]. Advanced Materials Research, 2013, 19 (1): 4562-4566.

3. Nicolas $X$, Benzaoui A, Xin S. Numerical simulation of thermoconvective flows and more uniform depositions in a cold wall rectangular APCVD reactor [J]. Crystal Growth, 2008, 310 (1): 174-186.

4. Chen W.R. A numerical study of laminar free convection heat transfer between inner sphere and outer vertical Cylinder [J]. International Journal of Heat and Mass Transfer, 2007, 50 (13-14) : 26562666.

5. Gamrat G, Favre-Marinet M, Le P.S. Numerical study of heat transfer over banks of rods in small

Reynolds number cross-flow [J]. International Journal of Heat and Mass Transfer, 2008, 51 (3-4): 853-864.

6. Nouri-Borujerdi A, Lavasani A.M. Experimental study of forced convection heat transfer from a cam shaped tube in cross flows [J]. International Journal of Heat and Mass Transfer, 2007. 50 (13-14): 26052611.

7. Yalcin H.G, Baskaya S. Sivrioglu M. Numerical analysis of natural convection heat transfer from rectangular shrouded fin arrays on a horizontal surface[J]. International Communications in Heat and Mass Transfer, 2008, 35 (3): 299-311.

8. Das A, Das B. Thermo-elastic stress distribution in three layered system [J]. Proc. Nat. acad Sci, 2001, 71(1): 21-31. 